\title{
Enhancement of Alkaline Hydrogen Oxidation Reaction of Ru-Ir Alloy Nanoparticles through Bifunctional Mechanism on Ru-Ir Pair Site
}

Kazutomo Ishikawa, ${ }^{1}$ Junya Ohyama, ${ }^{2,3 *}$ Keiichi Okubo, ${ }^{1}$ Kazumasa Murata, ${ }^{1}$ Atsushi

$$
\text { Satsuma } a^{1,3}
$$

${ }^{1}$ Graduate School of Engineering, Nagoya University, Furo-cho, Chikusa-ku, Nagoya 464-8603, Japan.

${ }^{2}$ Faculty of Advanced Science and Technology, Kumamoto University, 2-39-1

Kurokami, Chuo-ku, Kumamoto, 860-8555 Japan.

${ }^{3}$ Elements Strategy Initiative for Catalysts and Batteries (ESICB), Kyoto University, Katsura, Kyoto 615-8520, Japan

*ohyama@kumamoto-u.ac.jp 
Table S1. The amounts of precursor used in catalyst preparation

\begin{tabular}{ccc}
\hline Catalyst & $\mathrm{RuCl}_{3} \cdot \mathrm{xH}_{2} \mathrm{O}(\mathrm{mg})$ & $\mathrm{IrCl}_{3}(\mathrm{mg})$ \\
\hline $\mathrm{Ru} / \mathrm{C}$ & 60.22 & - \\
$\mathrm{Ru}-\mathrm{Ir}(3 / 1) / \mathrm{C}$ & 36.85 & 15.07 \\
$\mathrm{Ru}-\mathrm{Ir}(1 / 1) / \mathrm{C}$ & 20.75 & 25.45 \\
$\mathrm{Ru}-\mathrm{Ir}(2 / 3) / \mathrm{C}$ & 15.63 & 28.75 \\
$\mathrm{Ru}-\mathrm{Ir}(1 / 3) / \mathrm{C}$ & 8.98 & 33.04 \\
$\mathrm{Ir} / \mathrm{C}$ & - & 38.83 \\
\hline
\end{tabular}

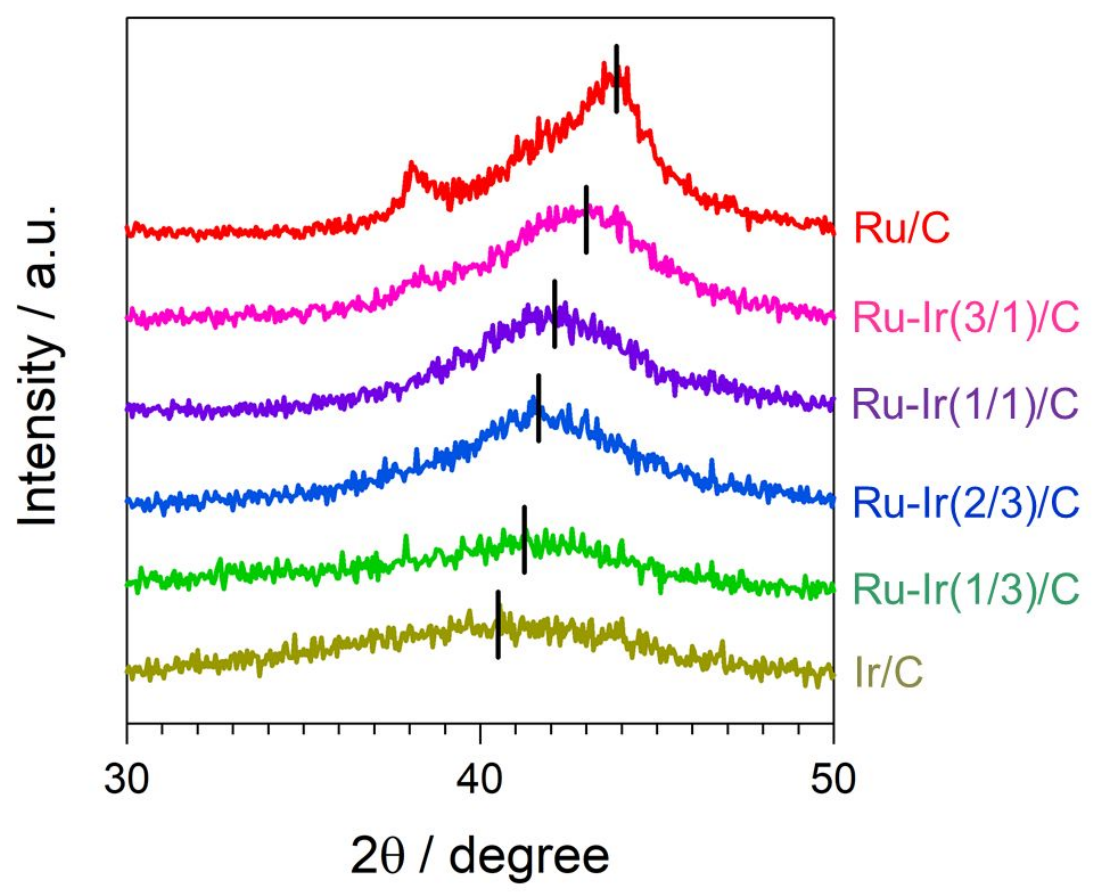

Figure S1. The zoomed XRD between 30 to $50^{\circ}$ of $\mathrm{Ru}-\mathrm{Ir} / \mathrm{C}$ with various $\mathrm{Ru} / \mathrm{Ir}$ compositions, together with those of $\mathrm{Ru} / \mathrm{C}$ and $\mathrm{Ir} / \mathrm{C}$. 

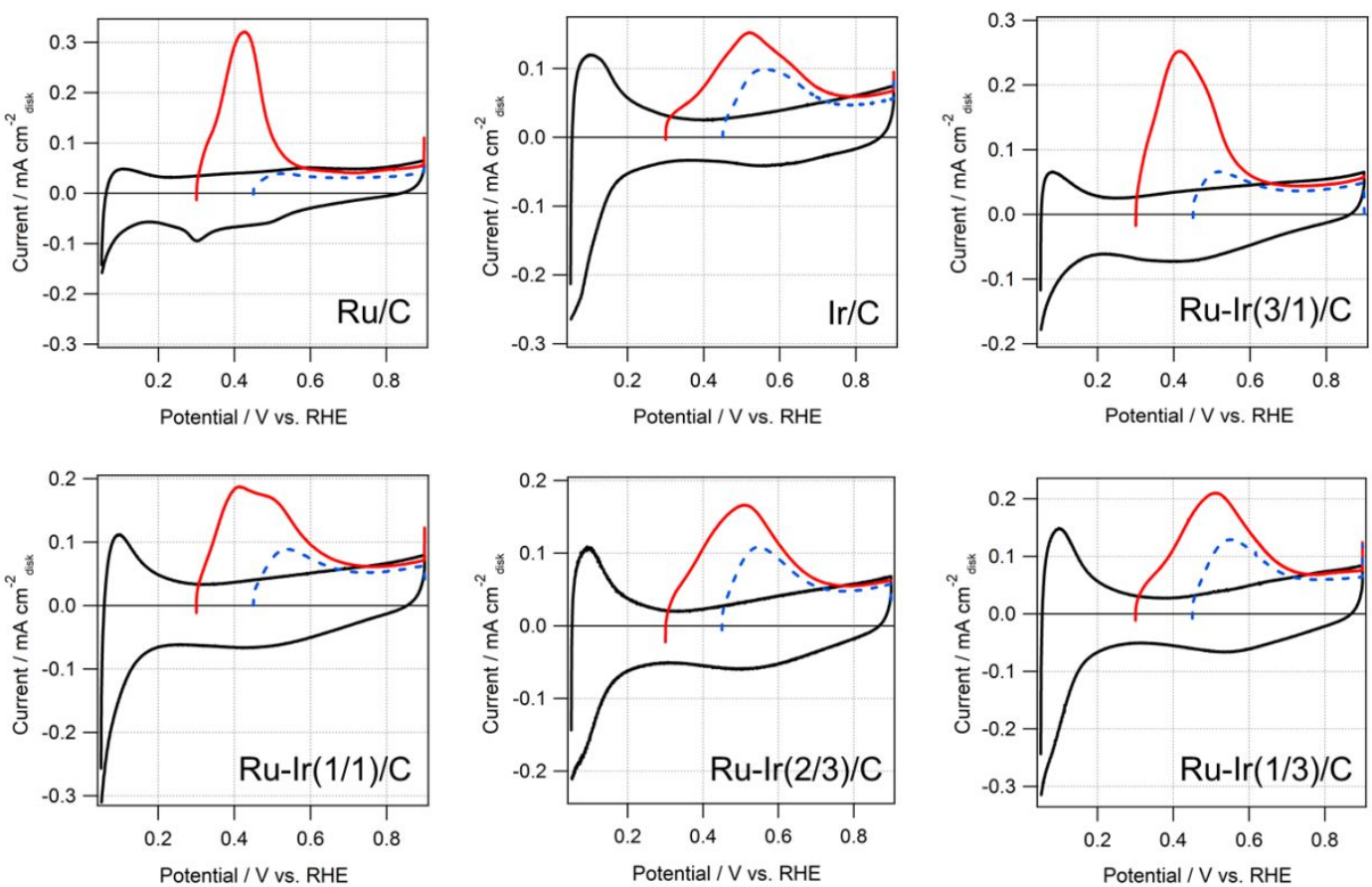

Figure S2. The $\mathrm{Cu}_{\mathrm{UPD}}$ stripping voltammograms of the catalysts from 0.3 to $0.9 \mathrm{~V}$ vs. RHE (solid red lines) and those from 0.45 to $0.9 \mathrm{~V}$ vs. RHE (dashed blue lines) in $\mathrm{H}_{2} \mathrm{SO}_{4}$ aqueous solution (0.1 M) containing $\mathrm{CuSO}_{4}(2 \mathrm{mM})$, together with the $\mathrm{CVs}$ in $\mathrm{H}_{2} \mathrm{SO}_{4}$ aqueous solution $(0.1 \mathrm{M})$ (solid black lines).

Table S2. Mass activity and specific activity of each catalyst

\begin{tabular}{lll}
\hline Catalyst & MA $\left(\mathrm{A} / \mathrm{mg}_{\text {metal }}\right)$ & $\mathrm{SA}\left(\mathrm{mA} / \mathrm{cm}^{2}{ }_{\text {metal }}\right)$ \\
\hline $\mathrm{Pt} / \mathrm{C}(\mathrm{TKK})$ & 0.120 & 0.174 \\
$\mathrm{Ru} / \mathrm{C}$ & 0.022 & 0.027 \\
$\mathrm{Ru}-\mathrm{Ir}(3 / 1) / \mathrm{C}$ & 0.148 & 0.165 \\
$\mathrm{Ru}-\mathrm{Ir}(1 / 1) / \mathrm{C}$ & 0.215 & 0.278 \\
$\mathrm{Ru}-\mathrm{Ir}(2 / 3) / \mathrm{C}$ & 0.210 & 0.283 \\
$\mathrm{Ru}-\mathrm{Ir}(1 / 3) / \mathrm{C}$ & 0.210 & 0.236 \\
$\mathrm{Ir} / \mathrm{C}$ & 0.120 & 0.146 \\
\hline
\end{tabular}




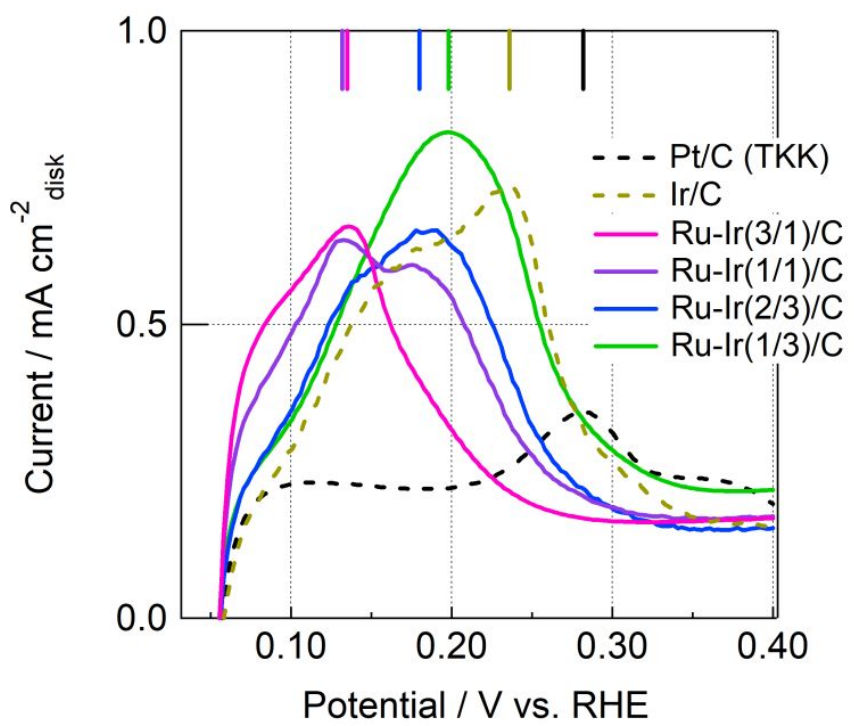

Figure S3. The zoomed CVs of the catalysts from 0.05 to $0.4 \mathrm{~V}$ vs. RHE. $\mathrm{H}_{\mathrm{UPD}}$ desorption peak potential is indicated by the colored lines.
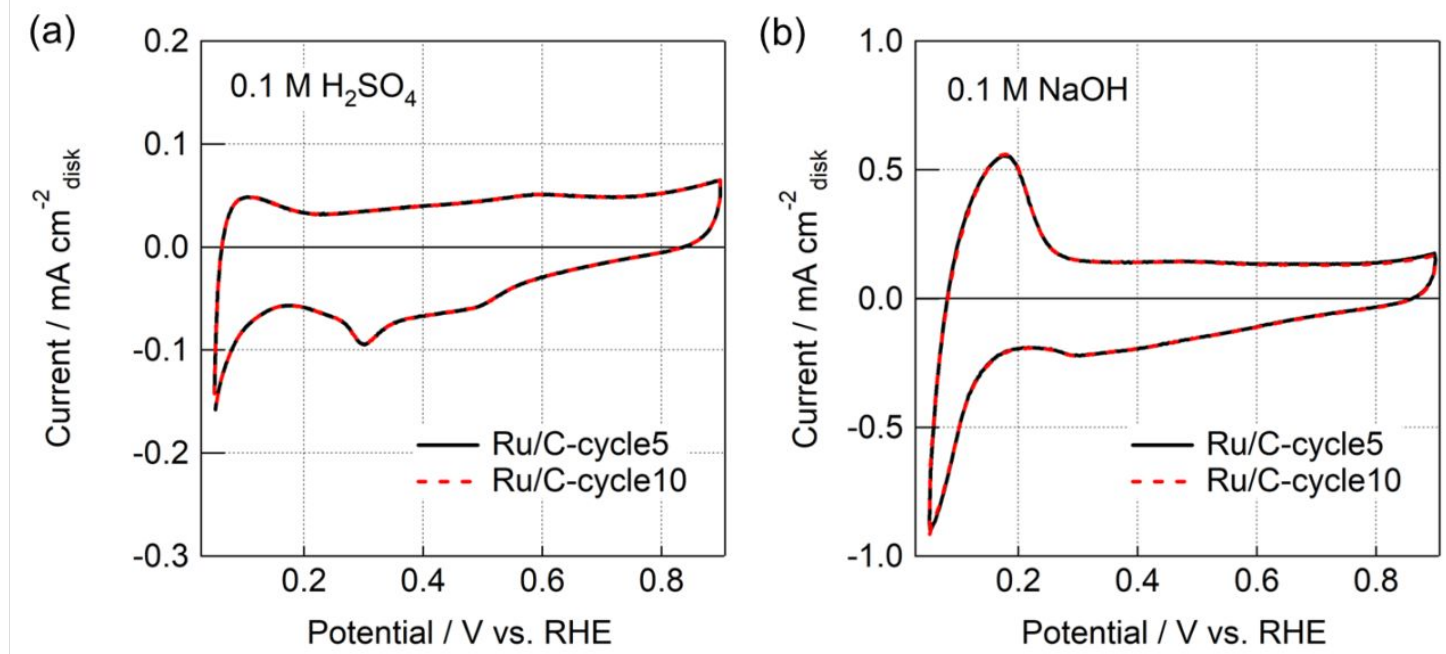

Figure S4. The $\mathrm{CVs}$ of $\mathrm{Ru} / \mathrm{C}$ from 0.05 to $0.9 \mathrm{~V}$ vs. RHE at $5^{\text {th }}$ (black solid line) and $10^{\text {th }}$ cycle (red dashed line): (a) in $\mathrm{H}_{2} \mathrm{SO}_{4}$ aqueous solution $(0.1 \mathrm{M})$; (b) in $\mathrm{NaOH}$ solution $(0.1 \mathrm{M})$. 


\section{Determination of Ru-Ir pair probability}

The probabilities of Ru-Ir, Ru-Ru, and Ir-Ir pair sites (Figure S5) were determined through the following calculations from the surface $\mathrm{Ir} / \mathrm{Ru}$ composition (determined by $\mathrm{Cu}_{\mathrm{UPD}}$ ) assuming that $\mathrm{Ru}$ and Ir are randomly distributed on the catalyst surface. Figure S6 shows a sample of the model surface structure used for the pair probability calculations, in which a core atom is packed by six atoms. In this model, Ru and Ir are randomly arranged to form a variety of patterns. Figures S7 and S8 show all patterns with Ir and $\mathrm{Ru}$, respectively, as the centers. The patterns were classified into 14 groups (groups $\mathrm{A}$ to $\mathrm{N}$ ) according to the pair ratio or the number of $\mathrm{Ru}$ and $\mathrm{Ir}$ atoms (Figures $\mathrm{S} 7$ and S8). The pair probability of each group at a given Ir/Ru composition $(x)$ was calculated from the probability for the formation of each group (A to N) multiplied by the number of patterns and the pair site ratio as follows:

$$
\left(\frac{1}{x}\right)^{n}\left(\frac{1}{1-x}\right)^{7-n} \times(\text { Number of pattern }) \times(\text { Pair ratio in the patten) } \text { (eq. S1) }
$$

where $x$ and $1-x$ are the surface compositions of $\operatorname{Ir}$ and $\mathrm{Ru}$, respectively, and $n$ and $7-n$ are the number of Ir and Ru atoms in the model, respectively $(n=1,2, \cdots, 7)$. The pair probability of each group is summed up to obtain the pair probability shown in Figure S5.

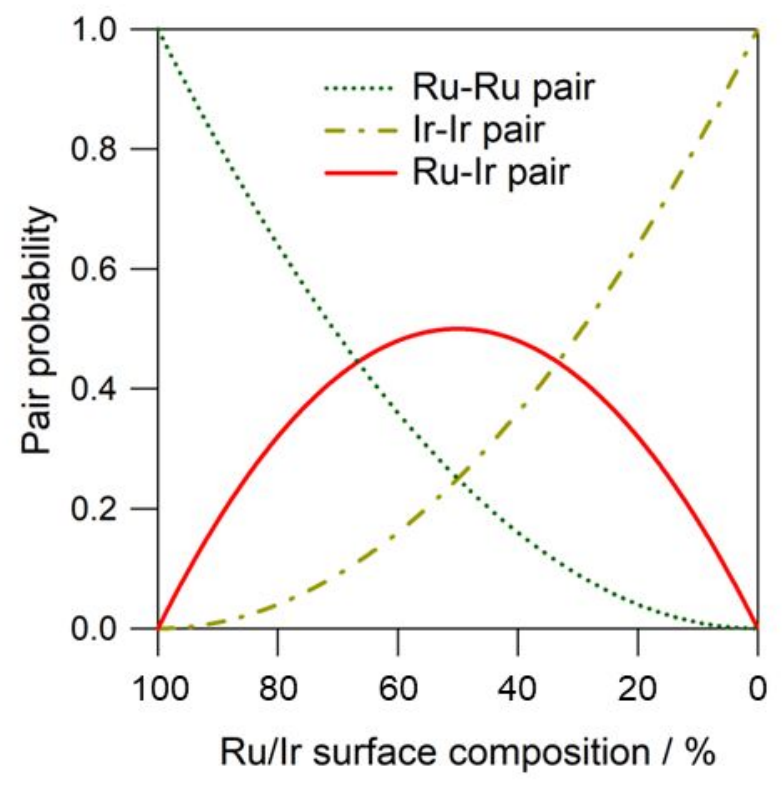

Figure S5. Pair probability of the metal-metal pair on the catalyst surface (Ru-Ru, Ir-Ir, and Ru-Ir pairs are indicated by green dotted line, yellow dashed line, and red solid line, respectively) 


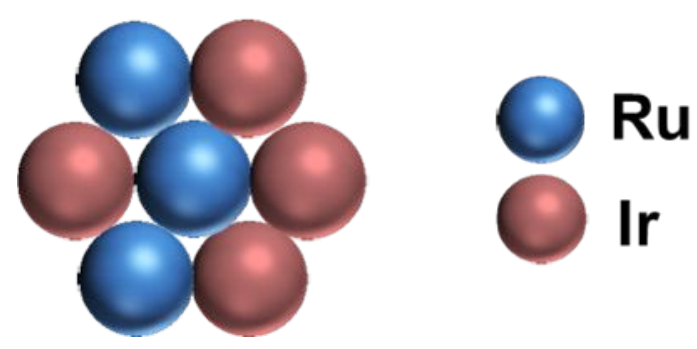

Figure S6. An example of the Ru-Ir arrangement in the model used to estimate the pair probability (Blue sphere: Ru atom; red sphere: Ir atom)

\begin{tabular}{|c|c|c|c|c|c|c|c|}
\hline Group & & & & $\mathrm{n}_{\mathrm{II}}$ & $\mathrm{n}_{\mathrm{Ru}}$ & Pattern images & $\begin{array}{l}\text { Number } \\
\text { of pattern }\end{array}$ \\
\hline A & 0 & 0 & 1 & 1 & 6 & 88 & 1 \\
\hline B & $\frac{1}{6}$ & 0 & $\frac{5}{6}$ & 2 & 5 & 89898 & 6 \\
\hline $\mathrm{C}$ & $\frac{1}{3}$ & 0 & $\frac{2}{3}$ & 3 & 4 & & 15 \\
\hline D & $\frac{1}{2}$ & 0 & $\frac{1}{2}$ & 4 & 3 & 0 & 20 \\
\hline $\mathrm{E}$ & $\frac{2}{3}$ & 0 & $\frac{1}{3}$ & 5 & 2 & & 15 \\
\hline $\mathrm{F}$ & $\frac{5}{6}$ & 0 & $\frac{1}{6}$ & 6 & 1 & & 6 \\
\hline $\mathrm{G}$ & 1 & 0 & 0 & 7 & 0 & 88 & 1 \\
\hline
\end{tabular}

Figure S7. The list of arrangement patterns when $\mathrm{Ir}$ is the center metal $\left(n_{I r}\right.$ and $n_{R u}$ are the numbers of Ir and Ru atoms, respectively) 


\begin{tabular}{|c|c|c|c|c|c|c|c|}
\hline Group & & $\begin{array}{l}\text { ir } 1 \\
\mathrm{u}-\mathrm{I}\end{array}$ & & $\mathrm{n}_{\text {II }}$ & $\mathrm{n}_{\mathrm{Ru}}$ & Pattern images & $\begin{array}{l}\text { Number } \\
\text { of pattern }\end{array}$ \\
\hline $\mathrm{H}$ & 0 & 0 & 1 & 6 & 1 & 88 & 1 \\
\hline I & 0 & $\frac{1}{6}$ & $\frac{5}{6}$ & 5 & 2 & 8 & 6 \\
\hline $\mathrm{J}$ & 0 & $\frac{1}{3}$ & $\frac{2}{3}$ & 4 & 3 & & 15 \\
\hline K & 0 & $\frac{1}{2}$ & $\frac{1}{2}$ & 3 & 4 & & 20 \\
\hline $\mathrm{L}$ & 0 & $\frac{2}{3}$ & $\frac{1}{3}$ & 2 & 5 & & 15 \\
\hline M & 0 & $\frac{5}{6}$ & $\frac{1}{6}$ & 1 & 6 & జి\% & 6 \\
\hline $\mathrm{N}$ & 0 & 1 & 0 & 0 & 7 & 8 & 1 \\
\hline
\end{tabular}

Figure S8. The list of arrangement patterns when Ru is the center metal $\left(n_{I r}\right.$ and $n_{R u}$ are the numbers of Ir and Ru atoms, respectively)

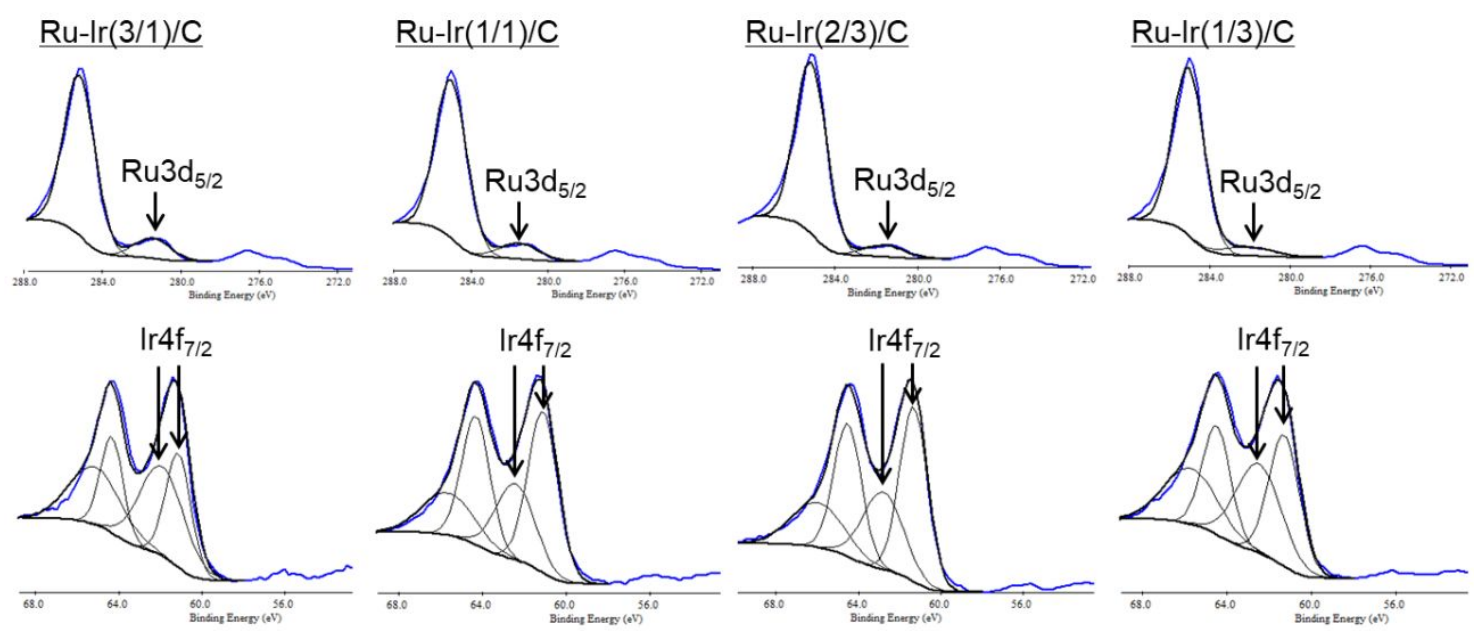

Figure S9. The XPS spectra of all Ru-Ir/C alloy catalysts (the upper side: Ru3d spectra, the lower side: Ir4f spectra). The surface composition was calculated from the ratio of $\mathrm{Ru} \mathrm{d}_{5 / 2}$ peak area and $\mathrm{Ir}_{4} \mathrm{f}_{7 / 2}$ peak area in order to support the $\mathrm{Ru} / \mathrm{Ir}$ surface composition determined by the $\mathrm{Cu}_{\mathrm{UPD}}$, 


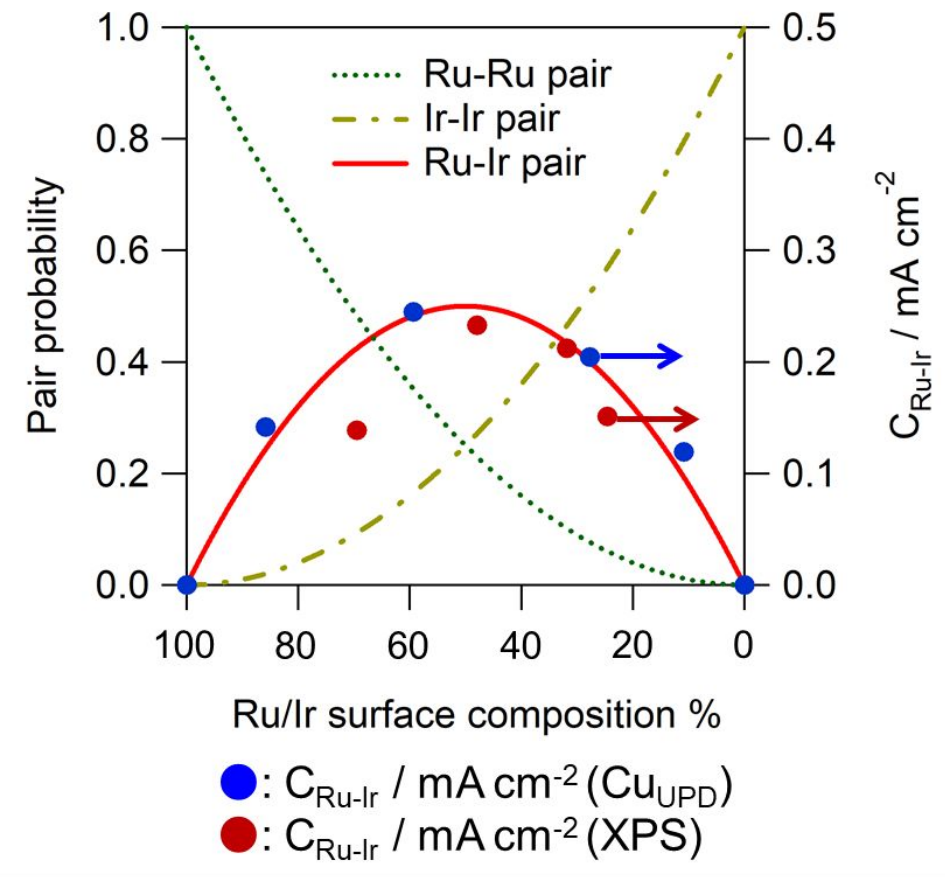

Figure S10. The relationship between Ru/Ir surface composition and the contribution of Ru-Ir pair to the $\mathrm{SA}\left(\mathrm{C}_{\mathrm{Ru}-\mathrm{Ir}}\right)$ Red circles indicate the $\mathrm{C}_{\mathrm{Ru}-\mathrm{Ir}}$ evaluated from surface composition obtained by XPS analysis; blue circles indicate the $\mathrm{C}_{\mathrm{Ru}-\mathrm{Ir}}$ evaluated from surface composition obtained by $\mathrm{Cu}_{\mathrm{UPD}}$ method. 

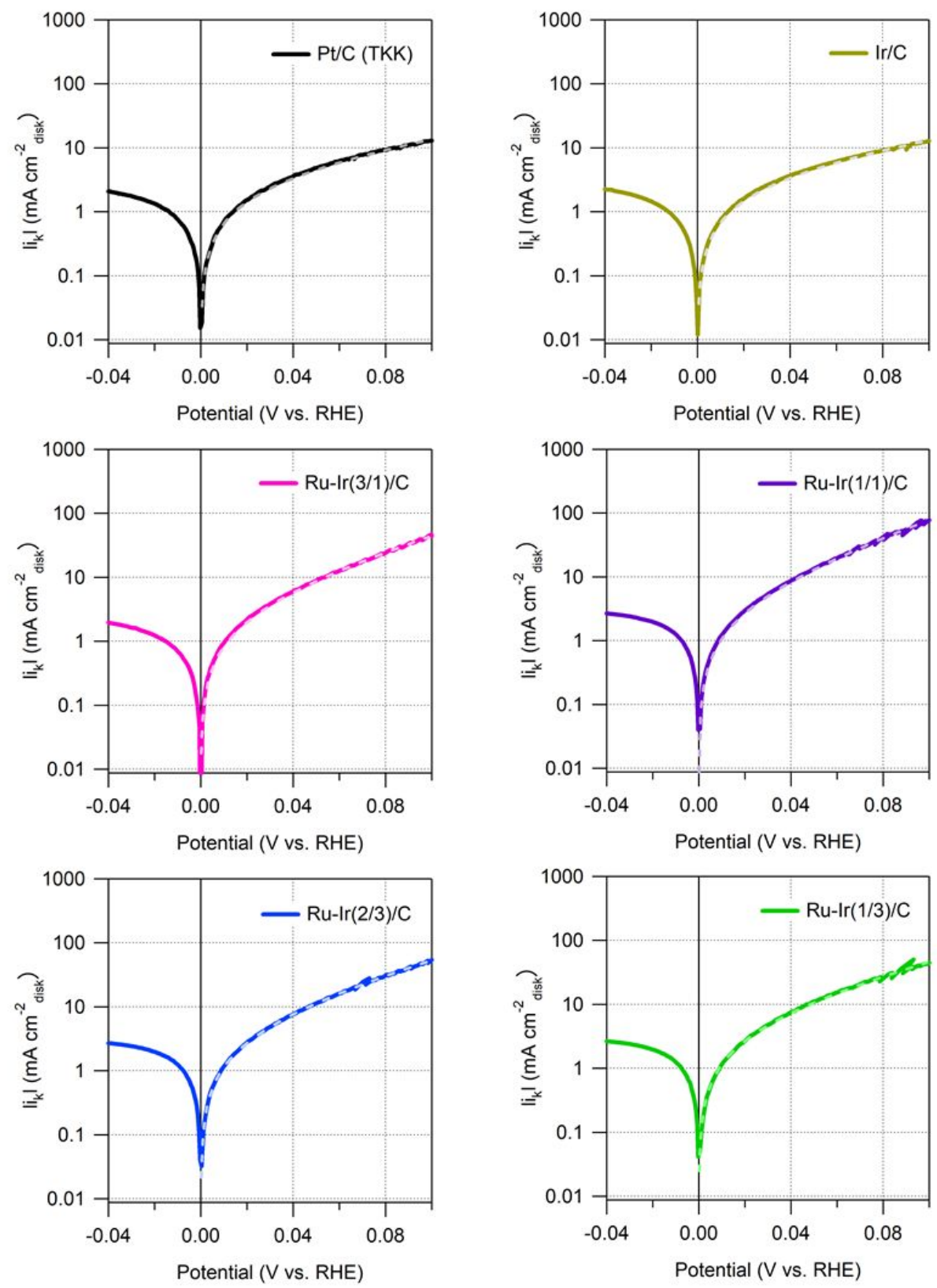

Figure S11. Tafel plots of $\mathrm{Pt} / \mathrm{C}, \mathrm{Ir} / \mathrm{C}$, and $\mathrm{Ru}-\mathrm{Ir} / \mathrm{C}$ for different $\mathrm{Ru} / \mathrm{Ir}$ compositions (The solid lines represent the Tafel plots obtained from the measured LSVs, and the dashed lines represent the curves fitted using the Butler-Volmer equation) 